\title{
Name of Fixative
}

National Cancer Institute

\section{Source}

National Cancer Institute. Name of Fixative. NCI Thesaurus. Code C128948.

The name of the compound that preserves tissues and cells for microscopic study. 